\title{
Kallikrein-related peptidase-4 (KLK4): role in enamel formation and revelations from ablated mice
}

\author{
John D. Bartlett ${ }^{1,2 *}$ and James P. Simmer ${ }^{3}$ \\ ${ }^{1}$ Harvard School of Dental Medicine, Boston, MA \\ 2 Department of Mineralized Tissue Biology, The Forsyth Institute, Cambridge, MA \\ ${ }^{3}$ Department of Biological and Material Sciences, University of Michigan School of Dentistry, Ann Arbor, MI, USA
}

\section{Edited by:}

Megan Pugach-Gordon, The Forsyth Insitute, USA

Reviewed by:

Tom Diekwisch, University of Illinois at Chicago, USA

Michael Paine, University of

Southern California, USA

${ }^{*}$ Correspondence:

John D. Bartlett, Harvard School of Dental Medicine; Department of Mineralized Tissue Biology, The

Forsyth Institute, 245 First Street,

Cambridge, MA 02142, USA

e-mail: jbartlett@forsyth.org
Enamel development occurs in stages. During the secretory stage, a soft protein rich enamel layer is produced that expands to reach its final thickness. During the maturation stage, proteins are removed and the enamel matures into the hardest substance in the body. KLK4 is expressed during the transition from secretory to the maturation stage and its expression continues throughout maturation. KLK4 is a glycosylated chymotrypsin-like serine protease that cleaves enamel matrix proteins prior to their export out of the hardening enamel layer. Mutations in $K L K 4$ can cause autosomal recessive, non-syndromic enamel malformations in humans and mice. KIk4 ablated mice initially have normal-looking teeth with enamel of full thickness. However, the enamel is soft and protein-rich. Three findings are notable from Klk4 ablated mice: first, enamel rods fall from the interrod enamel leaving behind empty holes where the enamel fractures near the underlying dentin surface. Second, the $\sim 10,000$ crystallites that normally fuse to form a solid enamel rod fail to grow together in the ablated mice and can fall out of the rods. Third, and most striking, the crystallites grow substantially in width and thickness (a- and b-axis) in the ablated mice until they almost interlock. The crystallites grow in defined enamel rods, but interlocking is prevented presumably because too much protein remains. Conventional thought holds that enamel proteins bind specifically to the sides of enamel crystals to inhibit growth in width and thickness so that the thin, ribbon-like enamel crystallites grow predominantly in length. Results from KIk4 ablated mice demonstrate that this convention requires updating. An alternative mechanism is proposed whereby enamel proteins serve to form a mold or support structure that shapes and orients the mineral ribbons as they grow in length. The remnants of this support structure must be removed by KLK4 so that the crystallites can interlock to form fully hardened enamel.

Keywords: enamel development, MMP20, amelogenin, ameloblastin, enamelin, enamel crystallites, enamel rods

\section{INTRODUCTION}

The enamel layer covers the crown of the tooth and is unique because it is an epithelially-derived calcified tissue and becomes the hardest substance in the body. Its hardness is between that of iron and carbon steel, but enamel has a higher elasticity (Newbrun and Pigman, 1960). Enamel hardness is a function of its high mineral content. Unlike bone and dentin (20-30\% organic material by weight), fully formed enamel contains very little protein (less than $1 \%$ organic material) (Lefevre and Manly, 1938; Deakins and Volker, 1941). Enamel mineral is very similar to hydroxyapatite (HAP) $\left[\mathrm{Ca}_{5} \mathrm{OH}\left(\mathrm{PO}_{4}\right)_{3}\right]$, but also contains low percentages of carbonate, sodium, and magnesium. Therefore within the body, teeth are the most resistant to deterioration and have been examined extensively for anthropological studies.

But, what are the developmental and mechanistic processes that make enamel harder than the cementum formed along the tooth root, the dentin underlying the enamel layer, and the skeletal bones? The ameloblasts are a single cell layer that cover the developing enamel and are responsible for enamel composition. Enamel development (amelogenesis) can be broken down into three defined stages: secretory, transition and maturation. The stages are defined by the morphology and function of the ameloblasts. Dentin mineralizes first and pre-ameloblasts transform into secretory stage ameloblasts by elongating into tall columnar cells and by forming Tomes' processes at their apical ends nearest the forming enamel. The Tomes' process is a conical structure that points toward the forming enamel matrix. Enamel matrix proteins are primarily secreted from one side of the Tomes' process (secretory face) and all ameloblasts within a row secrete protein from the same side of their Tomes' processes. The first formed enamel ribbons grow between the dentin crystals perhaps by mineralizing around dentin proteins such as collagen. At their growing tips near the Tomes' process, secretory stage enamel ribbons are only about $1.5 \mathrm{~nm}$ thick and $15 \mathrm{~nm}$ wide (Daculsi and Kerebel, 1978; Cuisinier et al., 1992) and these ribbons are extended until they span the entire thickness of the enamel layer. Approximately 10,000 parallel mineral ribbons are present in each enamel rod (Daculsi et al., 1984). A rod is about $5 \mu \mathrm{m}$ 
in cross-sectional diameter (Skobe and Stern, 1980) and each is generated by a single ameloblast (Skobe, 1977). Enamel ribbons elongate at the mineralization front where enamel proteins are secreted (Ronnholm, 1962). As the ameloblasts secrete large amounts of enamel matrix proteins, they move away from the dentin surface so that the nascent enamel layer can thicken. The mineral ribbons crystallize into HAP within the rod and will grow progressively in c-axis length parallel to one another as the ameloblasts move progressively away from the dentin surface. The crystallites are surrounded with abundant proteins that prevent them from fusing into a solid rod. The secretory stage enamel is therefore protein rich and has a soft cheese-like consistency.

During the secretory stage, ameloblasts not only move away from the dentin as the enamel thickens, but they also move in groups that slide by one another and this movement culminates in the characteristic decussating enamel prism pattern observed in rodent incisors (Reith and Ross, 1973) or the entwined gnarled prism pattern seen in human molars (Boyde, 1989). Secretory stage ameloblasts secrete four different proteins into the enamel matrix. Three are "structural" proteins and one is a proteinase. The structural proteins are amelogenin (AMELX), ameloblastin (AMBN), enamelin (ENAM), and the proteinase is matrix metalloproteinase-20 (MMP20, enamelysin). Amelogenin comprises approximately $80-90 \%$ of the organic matter within the secretory stage enamel matrix and ameloblastin and enamelin comprise roughly 5 and 3-5\%, respectively (Fincham et al., 1999; Hu et al., 2007). MMP20 is present in trace amounts. The precise function of these proteins remains unclear. However, human mutations in AMELX (Hu et al., 2012), ENAM (Rajpar et al., 2001), and MMP20 (Kim et al., 2005; Ozdemir et al., 2005; Lee et al., 2010; Gasse et al., 2013) genes and mouse knockout models (Gibson et al., 2001; Caterina et al., 2002; Fukumoto et al., 2004; Masuya et al., 2005; Seedorf et al., 2007; Hu et al., 2008) have definitively demonstrated that each of these proteins are absolutely required for proper enamel formation. This conclusion is supported by the observation that the genes encoding secretory stage enamel proteins are consistently pseudogenized in vertebrates that have lost the ability to make teeth, or specifically dental enamel, during evolution (Meredith et al., 2009, 2011, 2013). By the end of the secretory stage the enamel layer has achieved its full thickness. It is not until the end of the maturation stage when the proteins are almost completely removed, that the enamel achieves its final hardened form.

As the ameloblasts enter the transition stage, they no longer move relative to each other. They retract their Tomes' processes and transition into shorter and fatter maturation stage cells and, at the enamel surface, start modulating between ruffle and smooth-ended cells (Smith, 1998). It is during the maturation stage that ameloblasts actively secrete kallikrein-related peptidase-4 (KLK4) to help remove the mass of previously secreted and partially hydrolyzed (by MMP20) matrix proteins from the enamel layer so that the crystallites can expand, coalesce and fuse with adjacent crystals (Simmer et al., 2009). This strengthens the enamel rods and forms the most highly mineralized substance in the body. Therefore, unlike cementum, dentin and bone, the proteins responsible for mineralization are removed from enamel so that the enamel can attain its final hardened form. Also, relative to the other mineralized tissues, the entwined rod and interrod enamel forms a more highly ordered $3 \mathrm{D}$ structure that is highly resistant to occlusal forces. The stages of enamel development and the developmental processes as the enamel forms are remarkably similar in different mammalian species (Weinmann et al., 1942; Robinson et al., 1988). Rodents have continuously erupting incisors so every developmental stage is always present in specific locations along the forming rodent incisor.

\section{ENAMEL PROTEINASES}

The proteinase expressed during the secretory through early maturation stage is MMP20 (Begue-Kirn et al., 1998) and the proteinase expressed from the transition through maturation stages is KLK4 (Hu et al., 2002). To date, these are the only two proteinases proven to be secreted into the enamel matrix (Bartlett, 2013). Both proteinases are present in small amounts during enamel development and each proteinase was separately cloned by performing PCR-based homology cloning (Bartlett et al., 1996; Simmer et al., 1998). KLK4 was originally named enamel matrix serine proteinase-1 (EMSP1) (Simmer et al., 1998), but its name was changed to KLK4 because the gene encoding KLK4 locates within the kallikrein gene cluster.

Human and mouse mutations in both MMP20 (Caterina et al., 2002; Kim et al., 2005; Ozdemir et al., 2005; Lee et al., 2010; Gasse et al., 2013) and KLK4 (Hart et al., 2004; Simmer et al., 2009; Wang et al., 2013) cause severe enamel malformations and therefore demonstrate that no other proteinase has an extensive overlapping function with either of these proteinases. If this were the case, no severe enamel phenotype would likely occur if the activity of MMP20 or KLK4 were compromised. Furthermore, accumulated porcine secretory stage enamel protein cleavage products have been extensively characterized and MMP20 specifically cleaves recombinant enamel proteins in vitro to generate the full spectrum of cleavages that occur in vivo (Ryu et al., 1999; Nagano et al., 2009). Others have proposed that MMP9 is present within secretory stage developing enamel (Feng et al., 2012). However, this claim is uncertain as MMP20 activity can explain all of the secretory stage amelogenin cleavages and MMP9 mutations cause metaphyseal anadysplasia, which is not associated with enamel defects (Lausch et al., 2009). Similarly, chymotrypsin C is associated with enamel formation (Lacruz et al., 2011). However, although loss of CTRC function is a risk factor for pancreatitis, an associated enamel phenotype has not been described (Zhou and Sahin-Toth, 2011). Signal-peptide-peptidase-like 2a (SPPL2A) is a membrane bound protease in lysosomes/late endosomes that is expressed by enamel epithelium during the secretory and maturation stages of amelogenesis. Spll2a null mice show defective enamel, highlighting the importance of intracellular degradation of enamel proteins reabsorbed by endocytosis (Bronckers et al., 2013). Although it is likely that several proteases degrade enamel proteins within ameloblast lysosomes, MMP20, and KLK4 remain the only proteinases that are known to be secreted into the enamel matrix (Bartlett, 2013).

\section{DISCOVERY OF KLK4}

In 1977 a protease was purified from pig enamel (Fukae et al., 1977) that was later demonstrated to be inhibited by serine proteinase inhibitors phenylmethylsulfonyl fluoride (PMSF) and 
diisopropylfluoro phosphate (DIFP) (Shimizu et al., 1979). This protease was expressed during the early maturation stage when the enamel proteins are reabsorbed from the hardening enamel (Overall and Limeback, 1988). KLK4 was eventually cloned by PCR-based homology cloning from porcine cDNA with subsequent screening of a porcine cDNA library (Simmer et al., 1998). The porcine KLK4 preproenzyme is composed of 254 amino acids while the proenzyme has 230 residues and the active form has 224 amino acids (Simmer et al., 1998). The KLK4 genes of both mouse and human have six exons the first of which is noncoding. The mouse Klk4 gene is approximately $10 \mathrm{~kb}$ in size and locates in cytogenic region B2 on mouse chromosome 7 (Hu et al., $2000 \mathrm{~b})$. The human $K L K 4$ gene is approximately $7 \mathrm{~kb}$ in size and is located near the telomere of chromosome 19 (19q13.3-19q13.4) in a cluster of genes including the KLK family of serine proteases. Its gene exon/intron structure and protein domain structure is identical to that of the mouse (Hu et al., 2000b). Thus, because KLK4/EMSP1 was cloned after MMP20, it became the second proteinase identified by name that is secreted into the developing enamel matrix.

\section{KLK4 TISSUE LOCALIZATION}

KLK4 is a glycosylated, chymotrypsin-like serine protease that is expressed and secreted by transition to maturation stage ameloblasts (Hu et al., 2000a,b, 2002). KLK4 protein has not been isolated from any tissue other than from developing teeth (Ryu et al., 2002; Nagano et al., 2009). However, several studies have performed immunoassays or $\mathrm{qPCR}$ techniques to identify KLK4 in various tissues and many of these studies conflict with one another as to exactly where KLK4 is expressed (reviewed in Simmer et al., 2011b). To definitively identify where KLK4 is expressed, a gene targeted mouse strain was developed. These mice have a LacZ reporter gene with a mouse nuclear localization signal (NLS- $\beta$ gal) inserted at the natural Klk4 translation initiation site. Therefore, with these mice, locations of KLK4 expression were identified within tissues by using $\beta$-galactosidase histochemistry (Simmer et al., 2009). KLK4 was expressed highly in maturation stage ameloblasts (Figure 1) and low levels of KLK4 expression were observed in the striated ducts of the submandibular salivary gland and in small patches of prostate epithelia. Furthermore, in these Klk4 LacZ knock-in mice, no obvious morphological abnormalities were observed in any of the non-dental tissues examined suggesting that their normal development is not Klk4 dependent (Simmer et al., 2011b). As is true for MMP20, it appears that the only essential, non-overlapping function of KLK4 is in enamel development.

\section{KLK4 ACTIVATION}

It is not known how KLK4 is activated in vivo. Removal of the KLK4 propeptide is essential for activation because it allows a salt linkage to form between the new $\mathrm{N}$-terminus and the side chain of Asp194 and this is essential for enzyme activity (Scully et al., 1998; Debela et al., 2006). Unlike the other kallikrein-related peptidases, KLK4 has a Gln as the last residue of its propeptide and not an Arg or Lys which means that KLK4 cannot be activated by trypsin-like enzymes (Lundwall and Brattsand, 2008). KLK4 cannot activate itself, but can be activated by MMP20 and thermolysin in vitro (Ryu et al., 2002). However, KLK4 is active in Mmp20 ablated mice (Yamakoshi et al., 2011) so MMP20 cannot be the sole KLK4 activator. Previously it was shown that dipeptidyl peptidase I (Cathepsin C, CTSC) activates KLK4 in vitro (Tye et al., 2009). In the enamel organ, CTSC is expressed at progressively increasing levels as development progresses to the early maturation stage when KLK4 begins its expression. Therefore, it remains a possibility that this cysteine aminopeptidase is the primary enzyme that activates KLK4.

\section{KLK4 SUBSTRATE SPECIFICITY}

KLK4 was assessed for its substrate specificity by using recombinant KLK4 to screen tetrapeptide positional scanning synthetic combinatorial libraries (PS-SCL) (Matsumura et al., 2005). The identified preferred P1-P4 positions were:

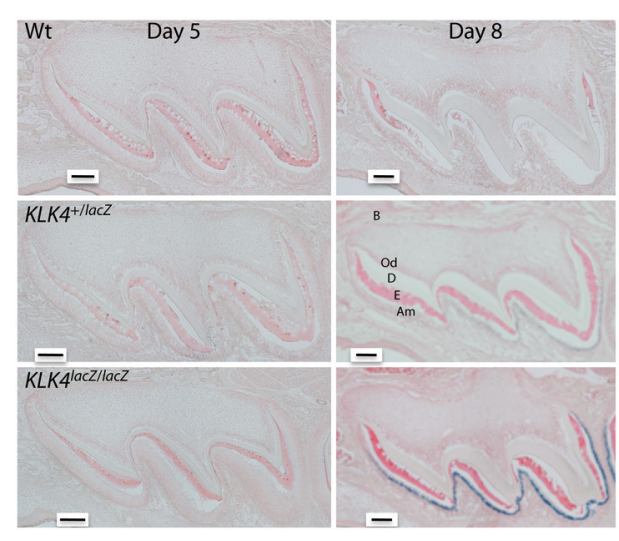

FIGURE 1 | Histochemical detection of $\beta$-galactosidase activity in maxillary first molars of wild-type $(\mathrm{Wt})$ heterozygous $\left(K I \mathrm{kS}^{+} / \mathrm{lacZ}\right)$ and homozygous $\left(K I k 4^{/ a c Z / l a c Z}\right)$ mice at postnatal days 5, 8, 11, and 14. LacZ histochemistry shows nuclear localized $\beta$-galactosidase activity where KLK4 is normally expressed. At the 5 -h incubation used, no endogenous (lysosomal) $\beta$-gal activity was observed and the

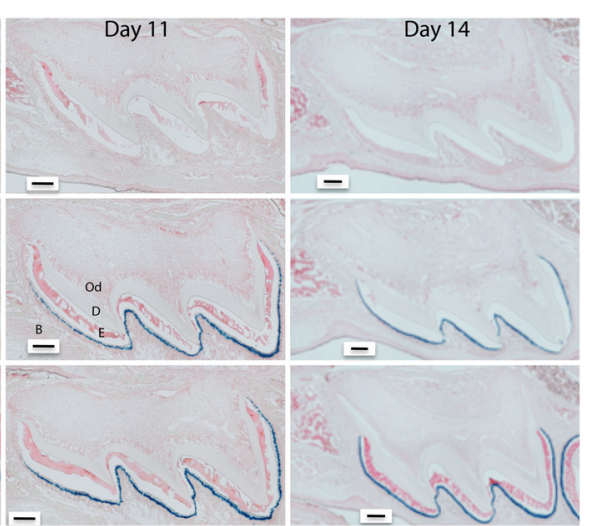

Wt mice were negative. In mouse molars, a positive signal was only observed in transition and maturation ameloblasts. No expression was observed in odontoblasts. B, Bone; Od, odontoblasts; D, dentin; E, enamel; Am, ameloblasts. Scale bars $=100 \mu \mathrm{m}$. This figure was reprinted with permission (S. Karger AG, Basel) from Simmer et al. (2011a). 
P1-Arg; P2-Gln/Leu/Val; P3-Gln/Ser/Val and P4-Ile/Val. The first report demonstrating that KLK4 cleaves amelogenin, used native porcine KLK4 incubated with recombinant pig amelogenin and this resulted in the generation of twelve cleavage products which were characterized by N-terminal sequencing (Ryu et al., 2002). It was subsequently demonstrated that the primary MMP20 $\mathrm{N}$-terminal cleavage product, tyrosine-rich amelogenin polypeptide (TRAP), was further cleaved by KLK4 which was consistent with the notion that KLK4 cleaves enamel matrix proteins into small peptides to facilitate their export out of the enamel as the enamel hardens (Nagano et al., 2009). Porcine ameloblastin was stably expressed and secreted from HEK293-N cells and was purified for digestion by KLK4. The cleavage products were characterized by N-terminal sequencing and KLK4 was shown to cleave ameloblastin at nine different sites (Chun et al., 2010). The $32 \mathrm{kDa}$ enamelin is presumed to be an MMP20 cleavage product and it is the only domain of the parent protein that accumulates in the deeper, more mature enamel layer. Native porcine KLK4 was incubated with native porcine $32 \mathrm{kDa}$ enamelin and the digestion products were fractionated by reverse-phase high-performance liquid chromatography (RP-HPLC) and characterized by Edman sequencing, amino acid analysis, and mass spectrometry. KLK4 digestion of the $32-\mathrm{kDa}$ enamelin generated nine major cleavage products (Yamakoshi et al., 2006). Therefore, KLK4 cleaves all the structural enamel matrix proteins that are known to be secreted into the enamel matrix. Recently, it was confirmed that MMP20 activates pro-KLK4 and strikingly, that active KLK4 cleaves and inactivates MMP20 (Yamakoshi et al., 2013). In effect, by activating KLK4, MMP20 inactivates itself. This mechanism of MMP20 inactivation is supported by evidence demonstrating that in $K l k 4$ ablated mice, MMP20 is active well into the maturation stage when MMP20 activity has normally ceased (Yamakoshi et al., 2011).

\section{HUMAN KLK4 MUTATIONS}

Two different human KLK4 mutations are known to cause autosomal recessive hypomaturation amelogenesis imperfecta. The first discovered is a nonsense mutation occurring upstream of the KLK4 catalytic domain (p.Trp153*). This tryptophan residue is completely conserved in mouse and pig KLK4 and expression of this mutated gene would result in a truncated protein lacking the final 101 amino acids which includes the catalytic triad (His71, Asp116, and Ser207). This homozygous mutation occurred in two female siblings and both their primary and permanent dentitions were similarly affected. The sibling's teeth were yellow-brown in color and were excessively sensitive to hot and cold. The enamel was normal in thickness, but radiographically showed only a slight increase in opacity over that of the underling dentin indicating a decreased enamel mineral content. This soft enamel fractured from the occlusal surfaces of the primary molars (Hart et al., 2004). No other phenotype resulted from this nonsense mutation in KLK4. The second human KLK4 mutation was recently discovered by use of whole exome sequencing which identified a single nucleotide deletion (p.Gly82Alafs*87) in both alleles of a 9 year-old female. The frameshift was in the third of five coding exons so the mutant KLK4 transcripts may have been degraded by nonsense-mediated decay. If translated, the mutant protein would lack the same catalytic triad that was also lacking in the first discovered KLK4 mutation. As for the previously discovered KLK4 mutation, the enamel covering this proband's teeth appeared normal in size and shape, but was discolored yellowbrown and chipped on multiple teeth. This proband was also secondarily affected with dental caries (Wang et al., 2013). No other phenotype was observed due to the nucleotide deletion in KLK4. Therefore, in humans KLK4 is essential for enamel to achieve its final hardened form, and that just as for MMP20, the only non-overlapping function of KLK4 is in dental enamel development.

\section{THE KLK4 KNOCKOUT/LACZ KNOCKIN MOUSE}

As stated above under KLK4 tissue localization, gene targeting was used to generate a mouse strain carrying a null allele of $K l k 4$ that has a nuclear $L a c Z$ reporter gene inserted directly into the $K l k 4$ translation initiation site. Therefore, the $L a c Z$ code was positioned in the same genomic context as wild-type Klk4 and so provided a sensitive tissue reporter for native Klk4 expression (Simmer et al., 2009). Other than a tooth phenotype, the Klk4 ablated mice were normal. The teeth were normal, the enamel attained normal thickness and no abnormalities were observed until the enamel reached the transition to early maturation stage of development. At this point, the normal export of enamel matrix proteins from the matrix back to the ameloblasts destined for lysosomal degradation was impeded. The enamel retained proteins that were normally removed and the soft, protein-rich enamel abraded from the mouse teeth (Figures $2 \mathrm{~A}-\mathrm{C}$ ). This strongly supports the belief that KLK4 functions to cleave enamel matrix proteins to facilitate their export out of the hardening enamel (Simmer et al., 2009). Unexpectedly, the rod enamel sometimes pulled away from interrod enamel. This left holes in the interrod enamel that were once filled by enamel rods (Figures 2D,E) (Simmer et al., 2009, 2011a). Backscatter scanning electron microscopy revealed that the enamel layer of Klk4 null mice is reasonably well-mineralized at the surface, but is progressively less mineralized with depth (Hu et al., 2011; Smith et al., 2011). This pattern suggests that extracellular degradation of enamel proteins by KLK4 facilitates the movement of proteins in the deeper enamel toward the surface for ameloblast endocytosis.

Another observation in the Klk4 null mice was that the lack of KLK4 activity prevented the individual crystals within the rod from growing sufficiently in width and thickness so that they could interlock with adjacent crystals. Strikingly, bunches of crystals appeared to fall out of the rods and separate into individual crystals (Figure 3) similar in appearance to strands (crystals) of "uncooked angel hair spaghetti" falling out of a circular bundle (rod). Although the normal rod pattern was present in the Klk4 ablated enamel, the $\sim 10,000$ crystallites within the rod failed to interlock properly and the crystallites fell from the rods (Simmer et al., 2009). Developmental analyses of $K l k 4$ null incisor enamel showed that percent mineral by weight increased almost identically to that occurring in wild-type mice until mid-maturation when a level of about $80 \%$ mineral by weight was attained. In contrast to wild-type enamel, the mineral content of the null mouse enamel remained unchanged as development progressed 


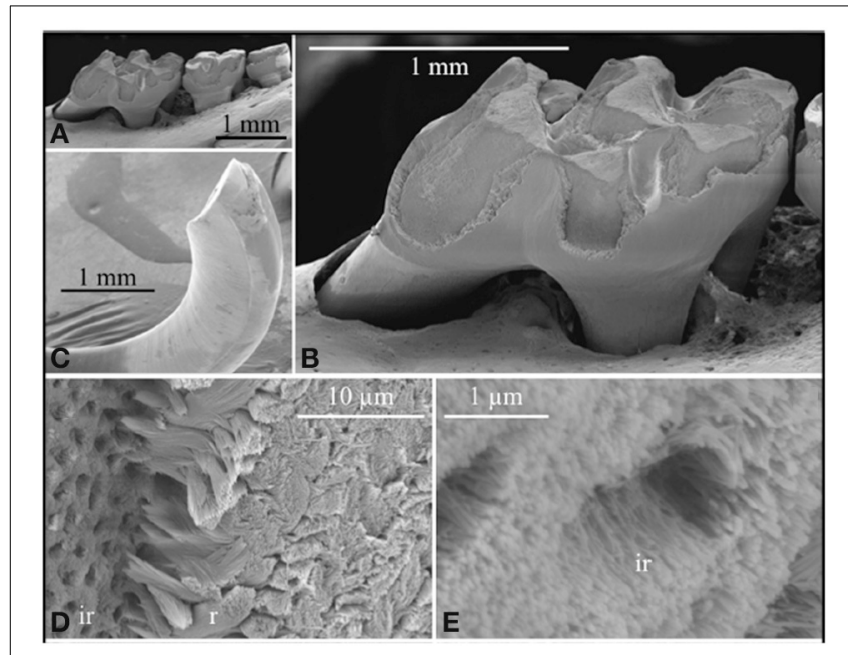

FIGURE 2 | Scanning electron micropscopy of the mandibular molars (A,B) and mandibular incisor (C-E) of a KIk4 null mouse at $\mathbf{7}$ weeks. The enamel of all molars showed a significant loss of enamel from all working surfaces (buccal cusps, occlusal surface, and marginal ridges) (A,B). Similarly, the enamel layer was abraded at the working (buccal) surface of the mandibular incisor at its tip (C). Higher magnification of the chipped area near the tip of the incisor showed the break was in the enamel layer, close to, but not at the DEJ. The broken surface appears to be composed of interrod (ir) enamel with holes where enamel rods ( $r$ ) had pulled out and separated (D) from the initial deposit of interrod enamel near the DEJ. The holes are too numerous to be made by odontoblastic processes penetrating the enamel (enamel spindles). The orientation of the crystallites on the walls of the holes is parallel to the direction of the tubular holes and to the crystallites between the holes (E). This figure was originally published by the American Society for Biochemistry and Molecular Biology in Simmer et al. (2009).

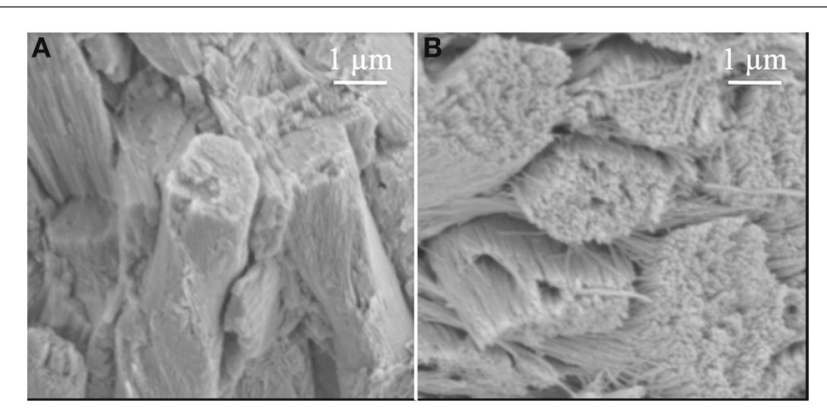

FIGURE 3 | Comparison of enamel rods from (A) wild-type and (B) KIk4 null mice. Enamel rods in wild-type mice have tightly packed crystallites that lose some aspect of their individuality. Enamel rods in the Klk4 null mice are composed of distinctly individual crystallites resembling angel hair spaghetti. Holes or vacancies in some rods give the impression that smaller bundles of crystallites broke at a slightly deeper level and slid out of the rod. This figure was originally published by the American Society for Biochemistry and Molecular Biology in Simmer et al. (2009).

through the maturation stage (Smith et al., 2011). This seminal finding indicated that enamel maturation advanced normally, even in the presence of abundant protein, but arrested when the residual protein physically blocked final crystal maturation by occupying the shrinking space between crystals. If amelogenins and/or the other proteins inhibited crystal maturation by selectively binding to the sides of enamel crystals, the inhibition would have occurred earlier and would have resulted in a more severe enamel phenotype. All-in-all, the Klk4 knockin/knockout mouse has revealed surprises about enamel formation and has forced us to reexamine some of our more firmly held beliefs about how crystallites grow in width and thickness and interlock to form an enamel rod.

\section{A MODIFIED THEORY OF ENAMEL DEVELOPMENT}

During the secretory stage, proteins are secreted into the enamel matrix and are quickly cleaved by MMP20. Selected enamel protein cleavage products accumulate within the matrix and as new proteins are secreted they also are cleaved so that an abundance of MMP20 cleavage products are present throughout the enamel layer as the entire enamel layer grows away (thickens) from the dentin. Previously it was demonstrated that enamel mineral first forms as amorphous calcium phosphate (ACP) (Bodier-Houlle et al., 2000; Beniash et al., 2009). ACP has no defined structure. It can be thought of as "grains of sand" that require a mold if it is to have defined 3D structure. However, as described above, the enamel crystallites have a very specific shape. They grow into long thin ribbons. So it is postulated that the MMP20 cleavage products form a mold to define the shape of each crystallite ribbon so that the ACP can attain the proper shape prior to its conversion into HAP. Therefore, the nucleation event for mineral formation would occur within the protein mold so that the ACP will form a proper 3D ribbon structure prior to when it crystallizes into HAP. It is envisioned that the crystallite ribbon molds protect the crystallite ribbons, much as packaging material protects the contents of a box, as the enamel crystallites elongate from the dentin surface to the eventual outer surface of the enamel layer. This new theory (Simmer et al., 2012) represents a departure from previous beliefs that amelogenin by itself initiates enamel formation and from the thought that amelogenin inhibits crystallite growth in width and thickness (Bartlett and Simmer, 1999). In summary, results from the $K l k 4$ knockin/knockout mouse have led us to reevaluate our theories of enamel formation because we now have attained a better understanding of the importance of KLK4 activity and why it is so critical in enamel development.

\section{ACKNOWLEDGMENTS}

Research reported in this publication was supported by the National Institute of Dental and Craniofacial Research of the National Institutes of Health under award numbers RO1DE016276 (John D. Bartlett) and R01DE019775 (James P. Simmer).

\section{REFERENCES}

Bartlett, J. D. (2013). Dental enamel development: proteinases and their enamel matrix substrates. ISRN Dent. 2013, 684607. doi: 10.1155/2013/684607

Bartlett, J. D., and Simmer, J. P. (1999). Proteinases in developing dental enamel. Crit. Rev. Oral Biol. Med. 10, 425-441. doi: 10.1177/10454411990100040101

Bartlett, J. D., Simmer, J. P., Xue, J., Margolis, H. C., and Moreno, E. C. (1996). Molecular cloning and mRNA tissue distribution of a novel matrix metalloproteinase isolated from porcine enamel organ. Gene 183, 123-128. doi: 10.1016/S0378-1119(96)00525-2

Begue-Kirn, C., Krebsbach, P. H., Bartlett, J. D., and Butler, W. T. (1998). Dentin sialoprotein, dentin phosphoprotein, enamelysin and ameloblastin: tooth-specific molecules that are distinctively expressed during murine dental differentiation. Eur. J. Oral Sci. 106, 963-970. doi: 10.1046/j.09098836.1998.eos106510.x 
Beniash, E., Metzler, R. A., Lam, R. S., and Gilbert, P. U. (2009). Transient amorphous calcium phosphate in forming enamel. J. Struct. Biol. 166, 133-143. doi: 10.1016/j.jsb.2009.02.001

Bodier-Houlle, P., Steuer, P., Meyer, J. M., Bigeard, L., and Cuisinier, F. J. (2000). High-resolution electron-microscopic study of the relationship between human enamel and dentin crystals at the dentinoenamel junction. Cell Tissue Res. 301, 389-395. doi: 10.1007/s004410000241

Boyde, A. (1989). "Enamel," in Handbook of Microscopic Anatomy, eds A. Oksche and L. Vollrath (Berlin: Springer-Verlag), 309-473.

Bronckers, A. L., Gueneli, N., Lullmann-Rauch, R., Schneppenheim, J., Moraru, A. P., Himmerkus, N., et al. (2013). The intramembrane protease SPPL2A is critical for tooth enamel formation. J. Bone Miner. Res. 28, 1622-1630. doi: 10.1002/jbmr.1895

Caterina, J. J., Skobe, Z., Shi, J., Ding, Y., Simmer, J. P., Birkedal-Hansen, H., et al. (2002). Enamelysin (matrix metalloproteinase 20)-deficient mice display an amelogenesis imperfecta phenotype. J. Biol. Chem. 277, 49598-49604. doi: 10.1074/jbc.M209100200

Chun, Y. H., Yamakoshi, Y., Yamakoshi, F., Fukae, M., Hu, J. C., Bartlett, J. D., et al. (2010). Cleavage site specificity of MMP-20 for secretory-stage ameloblastin. J. Dent. Res. 89, 785-790. doi: 10.1177/0022034510366903

Cuisinier, F. J., Steuer, P., Senger, B., Voegel, J. C., and Frank, R. M. (1992). Human amelogenesis. I: high resolution electron microscopy study of ribbon-like crystals. Calcif. Tissue Int. 51, 259-268. doi: 10.1007/BF00334485

Daculsi, G., and Kerebel, B. (1978). High-resolution electron microscope study of human enamel crystallites: size, shape, and growth. J. Ultrastruct. Res. 65, 163-172. doi: 10.1016/S0022-5320(78)90053-9

Daculsi, G., Menanteau, J., Kerebel, L. M., and Mitre, D. (1984). Length and shape of enamel crystals. Calcif. Tissue Int. 36, 550-555. doi: 10.1007/BF02405364

Deakins, M., and Volker, J. F. (1941). Amount of organic matter in enamel from several types of human teeth. J. Dent. Res. 20, 117-121. doi: 10.1177/00220345410200020201

Debela, M., Magdolen, V., Grimminger, V., Sommerhoff, C., Messerschmidt, A., Huber, R., et al. (2006). Crystal structures of human tissue kallikrein 4: activity modulation by a specific zinc binding site. J. Mol. Biol. 362, 1094-1107. doi: 10.1016/j.jmb.2006.08.003

Feng, J., Mcdaniel, J. S., Chuang, H. H., Huang, O., Rakian, A., Xu, X., et al. (2012). Binding of amelogenin to MMP-9 and their co-expression in developing mouse teeth. J. Mol. Histol. 43, 473-485. doi: 10.1007/s10735-012-9423-1

Fincham, A. G., Moradian-Oldak, J., and Simmer, J. P. (1999). The structural biology of the developing dental enamel matrix. J. Struct. Biol. 126, 270-299. doi: 10.1006/jsbi.1999.4130

Fukae, M., Tanabe, T., and Shimizu, M. (1977). Proteolytic enzyme activity in porcine immature enamel. Tsurumi Shigaku 3, 15-17.

Fukumoto, S., Kiba, T., Hall, B., Iehara, N., Nakamura, T., Longenecker, G., et al. (2004). Ameloblastin is a cell adhesion molecule required for maintaining the differentiation state of ameloblasts. J. Cell Biol. 167, 973-983. doi: $10.1083 /$ jcb. 200409077

Gasse, B., Karayigit, E., Mathieu, E., Jung, S., Garret, A., Huckert, M., et al. (2013). Homozygous and compound heterozygous MMP20 mutations in amelogenesis imperfecta. J. Dent. Res. 92, 598-603. doi: 10.1177/0022034513488393

Gibson, C. W., Yuan, Z. A., Hall, B., Longenecker, G., Chen, E., Thyagarajan, T., et al. (2001). Amelogenin-deficient mice display an amelogenesis imperfecta phenotype. J. Biol. Chem. 276, 31871-31875. doi: 10.1074/jbc.M104624200

Hart, P. S., Hart, T. C., Michalec, M. D., Ryu, O. H., Simmons, D., Hong, S., et al. (2004). Mutation in kallikrein 4 causes autosomal recessive hypomaturation amelogenesis imperfecta. J. Med. Genet. 41, 545-549. doi: 10.1136/jmg.2003.017657

Hu, J. C., Chan, H. C., Simmer, S. G., Seymen, F., Richardson, A. S., Hu, Y., et al. (2012). Amelogenesis imperfecta in two families with defined AMELX deletions in ARHGAP6. PLoS ONE 7:e52052. doi: 10.1371/journal.pone.0052052

Hu, J. C., Chun, Y. H., Al Hazzazzi, T., and Simmer, J. P. (2007). Enamel formation and amelogenesis imperfecta. Cells Tissues Organs 186, 78-85. doi: $10.1159 / 000102683$

Hu, J. C., Hu, Y., Smith, C. E., McKee, M. D., Wright, J. T., Yamakoshi, Y., et al. (2008). Enamel defects and ameloblast-specific expression in Enam knock-out/lacz knock-in mice. J. Biol. Chem. 283, 10858-10871. doi: 10.1074/jbc.M710565200

Hu, J. C., Ryu, O. H., Chen, J. J., Uchida, T., Wakida, K., Murakami, C., et al. (2000a). Localization of EMSP1 expression during tooth formation and cloning of mouse cDNA. J. Dent. Res. 79, 70-76. doi: 10.1177/00220345000790011301
Hu, J. C., Zhang, C., Sun, X., Yang, Y., Cao, X., Ryu, O., et al. (2000b). Characterization of the mouse and human PRSS17 genes, their relationship to other serine proteases, and the expression of PRSS17 in developing mouse incisors. Gene 251, 1-8. doi: 10.1016/S0378-1119(00)00203-1

Hu, J. C., Sun, X., Zhang, C., Liu, S., Bartlett, J. D., and Simmer, J. P. (2002). Enamelysin and kallikrein-4 mRNA expression in developing mouse molars. Eur. J. Oral Sci. 110, 307-315. doi: 10.1034/j.1600-0722.2002.21301.x

Hu, Y., Hu, J. C., Smith, C. E., Bartlett, J. D., and Simmer, J. P. (2011). Kallikreinrelated peptidase 4 , matrix metalloproteinase 20 , and the maturation of murine and porcine enamel. Eur. J. Oral Sci. 119(Suppl. 1), 217-225. doi: 10.1111/j.1600-0722.2011.00859.x

Kim, J. W., Simmer, J. P., Hart, T. C., Hart, P. S., Ramaswami, M. D., Bartlett, J. D., et al. (2005). MMP-20 mutation in autosomal recessive pigmented hypomaturation amelogenesis imperfecta. J. Med. Genet. 42, 271-275. doi: 10.1136/jmg.2004.024505

Lacruz, R. S., Smith, C. E., Smith, S. M., Hu, P., Bringas, P. Jr., Sahin-Toth, M., et al. (2011). Chymotrypsin C (caldecrin) is associated with enamel development. J. Dent. Res. 90, 1228-1233. doi: 10.1177/0022034511418231

Lausch, E., Keppler, R., Hilbert, K., Cormier-Daire, V., Nikkel, S., Nishimura, G., et al. (2009). Mutations in MMP9 and MMP13 determine the mode of inheritance and the clinical spectrum of metaphyseal anadysplasia. Am. J. Hum. Genet. 85, 168-178. doi: 10.1016/j.ajhg.2009.06.014

Lee, S. K., Seymen, F., Kang, H. Y., Lee, K. E., Gencay, K., Tuna, B., et al. (2010). MMP20 hemopexin domain mutation in amelogenesis imperfecta. J. Dent. Res. 89, 46-50. doi: 10.1177/0022034509352844

Lefevre, M. L., and Manly, R. S. (1938). Moisture, inorganic and organic contents of enamel and dentin from carious teeth. J. Am. Dent. Assoc. 24, 233-242.

Lundwall, A., and Brattsand, M. (2008). Kallikrein-related peptidases. Cell. Mol. Life Sci. 65, 2019-2038. doi: 10.1007/s00018-008-8024-3

Masuya, H., Shimizu, K., Sezutsu, H., Sakuraba, Y., Nagano, J., Shimizu, A., et al. (2005). Enamelin (Enam) is essential for amelogenesis: ENU-induced mouse mutants as models for different clinical subtypes of human amelogenesis imperfecta (AI). Hum. Mol. Genet. 14, 575-583. doi: 10.1093/hmg/ddi054

Matsumura, M., Bhatt, A. S., Andress, D., Clegg, N., Takayama, T. K., Craik, C. S., et al. (2005). Substrates of the prostate-specific serine protease prostase/KLK4 defined by positional-scanning peptide libraries. Prostate 62, 1-13. doi: 10.1002/pros.20101

Meredith, R. W., Gatesy, J., Cheng, J., and Springer, M. S. (2011). Pseudogenization of the tooth gene enamelysin (MMP20) in the common ancestor of extant baleen whales. Proc. Biol. Sci. 278, 993-1002. doi: 10.1098/rspb. 2010.1280

Meredith, R. W., Gatesy, J., Murphy, W. J., Ryder, O. A., and Springer, M. S. (2009). Molecular decay of the tooth gene Enamelin (ENAM) mirrors the loss of enamel in the fossil record of placental mammals. PLoS Genet. 5:e1000634. doi: 10.1371/journal.pgen.1000634

Meredith, R. W., Gatesy, J., and Springer, M. S. (2013). Molecular decay of enamel matrix protein genes in turtles and other edentulous amniotes. BMC Evol. Biol. 13:20. doi: 10.1186/1471-2148-13-20

Nagano, T., Kakegawa, A., Yamakoshi, Y., Tsuchiya, S., Hu, J. C., Gomi, K., et al. (2009). Mmp-20 and Klk4 cleavage site preferences for amelogenin sequences. J. Dent. Res. 88, 823-828. doi: 10.1177/0022034509342694

Newbrun, E., and Pigman, W. (1960). The hardness of enamel and dentine. Aust. Dent. J. 5, 210-217. doi: 10.1111/j.1834-7819.1960.tb01939.x

Overall, C. M., and Limeback, H. (1988). Identification and characterization of enamel proteinases isolated from developing enamel. Amelogeninolytic serine proteinases are associated with enamel maturation in pig. Biochem. J. 256, 965-972.

Ozdemir, D., Hart, P. S., Ryu, O. H., Choi, S. J., Ozdemir-Karatas, M., Firatli, E., et al. (2005). MMP20 active-site mutation in hypomaturation amelogenesis imperfecta. J. Dent. Res. 84, 1031-1035. doi: 10.1177/154405910508 401112

Rajpar, M. H., Harley, K., Laing, C., Davies, R. M., and Dixon, M. J. (2001). Mutation of the gene encoding the enamel-specific protein, enamelin, causes autosomal-dominant amelogenesis imperfecta. Hum. Mol. Genet. 10, 1673-1677. doi: 10.1093/hmg/10.16.1673

Reith, E. J., and Ross, M. H. (1973). Morphological evidence for the presence of contractile elements in secretory ameloblasts of the rat. Arch. Oral Biol. 18, 445-448. doi: 10.1016/0003-9969(73)90170-2

Robinson, C., Kirkham, J., Weatherell, J. A., Richards, A., Josephsen, K., and Fejerskov, O. (1988). Mineral and protein concentrations in enamel of 
the developing permanent porcine dentition. Caries Res. 22, 321-326. doi: $10.1159 / 000261131$

Ronnholm, E. (1962). An electron microscopic study of the amelogenesis in human teeth. I. The fine structure of the ameloblasts. J. Ultrastruct. Res. 6, 229-248. doi: 10.1016/S0022-5320(62)90055-2

Ryu, O., Hu, J. C., Yamakoshi, Y., Villemain, J. L., Cao, X., Zhang, C., et al. (2002). Porcine kallikrein-4 activation, glycosylation, activity, and expression in prokaryotic and eukaryotic hosts. Eur. J. Oral Sci. 110, 358-365. doi: 10.1034/j.1600-0722.2002.21349.x

Ryu, O. H., Fincham, A. G., Hu, C. C., Zhang, C., Qian, Q., Bartlett, J. D., et al. (1999). Characterization of recombinant pig enamelysin activity and cleavage of recombinant pig and mouse amelogenins. J. Dent. Res. 78, 743-750. doi: 10.1177/00220345990780030601

Scully, J. L., Bartlett, J. D., Chaparian, M. G., Fukae, M., Uchida, T., Xue, J., et al. (1998). Enamel matrix serine proteinase 1: stage-specific expression and molecular modeling. Connect. Tissue Res. 39, 111-122. doi: 10.3109/03008209809023917

Seedorf, H., Klaften, M., Eke, F., Fuchs, H., Seedorf, U., and Hrabe de Angelis, M. (2007). A mutation in the enamelin gene in a mouse model. J. Dent. Res. 86, 764-768. doi: 10.1177/154405910708600815

Shimizu, M., Tanabe, T., and Fukae, M. (1979). Proteolytic enzyme in porcine immature enamel. J. Dent. Res. 58, 782-789. doi: 10.1177/00220345790580023001

Simmer, J. P., Fukae, M., Tanabe, T., Yamakoshi, Y., Uchida, T., Xue, J., et al. (1998). Purification, characterization, and cloning of enamel matrix serine proteinase 1. J. Dent. Res. 77, 377-386. doi: 10.1177/00220345980770020601

Simmer, J. P., Hu, Y., Lertlam, R., Yamakoshi, Y., and Hu, J. C. (2009). Hypomaturation enamel defects in Klk4 Knockout/LacZ knockin mice. J. Biol. Chem. 284, 19110-19121. doi: 10.1074/jbc.M109.013623

Simmer, J. P., Hu, Y., Richardson, A. S., Bartlett, J. D., and Hu, J. C. (2011a). Why does enamel in Klk4-null mice break above the dentino-enamel junction? Cells tissues organs. 194, 211-215. doi: 10.1159/000324260

Simmer, J. P., Richardson, A. S., Smith, C. E., Hu, Y., and Hu, J. C. (2011b). Expression of kallikrein-related peptidase 4 in dental and non-dental tissues. Eur. J. Oral Sci. 119(Suppl. 1), 226-233. doi: 10.1111/j.1600-0722.2011. 00834.x

Simmer, J. P., Richardson, A. S., Hu, Y. Y., Smith, C. E., and Ching-Chun Hu, J. (2012). A post-classical theory of enamel biomineralization. . . and why we need one. Int. J. Oral Sci. 4, 129-134. doi: 10.1038/ijos.2012.59

Skobe, Z. (1977). Enamel rod formation in the monkey observed by scanning electron microscopy. Anat. Rec. 187, 329-334. doi: 10.1002/ar.1091870305

Skobe, Z., and Stern, S. (1980). The pathway of enamel rods at the base of cusps of human teeth. J. Dent. Res. 59, 1026-1032. doi: 10.1177/002203458005900 60401

Smith, C. E. (1998). Cellular and chemical events during enamel maturation. Crit. Rev. Oral Biol. Med. 9, 128-161. doi: 10.1177/10454411980090020101
Smith, C. E., Richardson, A. S., Hu, Y., Bartlett, J. D., Hu, J. C., and Simmer, J. P. (2011). Effect of kallikrein 4 loss on enamel mineralization: comparison with mice lacking matrix metalloproteinase 20. J. Biol. Chem. 286, 18149-18160. doi: 10.1074/jbc.M110.194258

Tye, C. E., Pham, C. T., Simmer, J. P., and Bartlett, J. D. (2009). DPPI may activate KLK4 during enamel formation. J. Dent. Res. 88, 323-327. doi: $10.1177 / 0022034509334240$

Wang, S. K., Hu, Y., Simmer, J. P., Seymen, F., Estrella, N. M., Pal, S., et al. (2013). Novel KLK4 and MMP20 mutations discovered by whole-exome sequencing. J. Dent. Res. 92, 266-271. doi: 10.1177/0022034513475626

Weinmann, J. P., Wessinger, G. D., and Reed, G. (1942). Correlation of chemical and histological investigations on developing enamel. J. Dent. Res. 21, 171-182. doi: 10.1177/00220345420210020701

Yamakoshi, Y., Hu, J. C., Fukae, M., Yamakoshi, F., and Simmer, J. P. (2006). How do enamelysin and kallikrein 4 process the 32-kDa enamelin? Eur. J. Oral Sci. 114(Suppl. 1), 45-51. doi: 10.1111/j.1600-0722.2006.00281.x

Yamakoshi, Y., Richardson, A. S., Nunez, S. M., Yamakoshi, F., Milkovich, R. N., Hu, J. C., et al. (2011). Enamel proteins and proteases in Mmp20 and Klk4 null and double-null mice. Eur. J. Oral Sci. 119(Suppl. 1), 206-216. doi: 10.1111/j.16000722.2011.00866.x

Yamakoshi, Y., Simmer, J. P., Bartlett, J. D., Karakida, T., and Oida, S. (2013). MMP20 and KLK4 activation and inactivation interactions in vitro. Arch. Oral Biol. 58, 1569-1577. doi: 10.1016/j.archoralbio.2013.08.005

Zhou, J., and Sahin-Toth, M. (2011). Chymotrypsin C mutations in chronic pancreatitis. J. Gastroenterol. Hepatol. 26, 1238-1246. doi: 10.1111/j.14401746.2011.06791.x

Conflict of Interest Statement: The Associate Editor declares that, despite being affiliated to the same institution as one of the authors, John D. Bartlett, the review process was handled objectively and no conflict of interest exists. The authors declare that the research was conducted in the absence of any commercial or financial relationships that could be construed as a potential conflict of interest.

Received: 06 May 2014; paper pending published: 23 May 2014; accepted: 10 June 2014; published online: 04 July 2014.

Citation: Bartlett JD and Simmer JP (2014) Kallikrein-related peptidase-4 (KLK4): role in enamel formation and revelations from ablated mice. Front. Physiol. 5:240. doi: 10.3389/fphys.2014.00240

This article was submitted to Craniofacial Biology, a section of the journal Frontiers in Physiology.

Copyright (C) 2014 Bartlett and Simmer. This is an open-access article distributed under the terms of the Creative Commons Attribution License (CC BY). The use, distribution or reproduction in other forums is permitted, provided the original author(s) or licensor are credited and that the original publication in this journal is cited, in accordance with accepted academic practice. No use, distribution or reproduction is permitted which does not comply with these terms. 